\title{
Advanced Oxidation Protein Product Promotes Oxidative Accentuation in Renal Epithelial Cells via the Soluble (Pro)renin Receptor-Mediated Intrarenal Renin-Angiotensin System and Nox4- $\mathrm{H}_{2} \mathrm{O}_{2}$ Signaling
}

\author{
Kai Xue $\mathbb{D}$, Yurong Wang $(\mathbb{D}$, Yan Wang $\mathbb{D}$, and Hui Fang $\mathbb{( i D}$ \\ Key Laboratory of Applied Pharmacology in Universities of Shandong, Department of Pharmacology, School of Pharmacy, \\ Weifang Medical University, Weifang, 261053 Shandong, China \\ Correspondence should be addressed to Hui Fang; fanghui8@126.com
}

Received 18 June 2021; Revised 20 September 2021; Accepted 9 November 2021; Published 26 November 2021

Academic Editor: Demetrios Kouretas

Copyright ( 2021 Kai Xue et al. This is an open access article distributed under the Creative Commons Attribution License, which permits unrestricted use, distribution, and reproduction in any medium, provided the original work is properly cited.

\begin{abstract}
Full-length (pro)renin receptor (fPRR), a research hotspot of the renin-angiotensin system (RAS), plays a serious role in kidney injury. However, the relationship between fPRR and advanced oxidation protein product (AOPP) remains largely unexplored. This study was aimed at exploring the effect of fPRR, especially its $28 \mathrm{kDa}$ soluble form called soluble PRR (sPRR), in AOPP-induced oxidative stress in HK-2 cells, a renal proximal tubular epithelial cell line. Incubation of HK-2 cells with $100 \mu \mathrm{g} / \mathrm{ml}$ AOPP resulted in significant upregulation of fPRR expression and caused an approximately fourfold increase in medium sPRR secretion. However, unmodified albumin did not demonstrate the same effects under the same concentration. Treatment of HK-2 cells with the site-1 protease (S1P) inhibitor PF429242 (40 $\mu \mathrm{M})$ or S1P siRNA significantly inhibited AOPP-induced sPRR generation. FPRR decoy inhibitor PRO20 and PF429242 treatment for $24 \mathrm{~h}$ remarkably attenuated the AOPP-induced upregulation of RAS components. Furthermore, PF429242 significantly reduced the AOPP-stimulated expression of NADPH oxidase 4 (Nox4) and $\mathrm{H}_{2} \mathrm{O}_{2}$ expression. The use of a small recombinant protein, named sPRR-His, reversed these alterations. In conclusion, these results provided the first demonstration of AOPPpromoted activation of sPRR. Increased renal proximal tubule Nox4-derived $\mathrm{H}_{2} \mathrm{O}_{2}$ contributed to the aggravation of oxidative stress. Targeting S1P-derived sPRR is a promising intervention strategy for chronic kidney disease.
\end{abstract}

\section{Introduction}

Chronic kidney disease (CKD) has emerged as a serious public health issue worldwide because of its high prevalence and high mortality associated with CKD progression and end-stage kidney disease; it is an independent risk factor for cardiovascular disease and all-cause mortality development $[1,2]$. Therefore, continuing to investigate potential treatments to prevent chronic kidney injury is important.

Investigations suggested the critical role of oxidative stress in the pathogenesis, progression, and complications of CKD [3]. The NADPH oxidase (Nox) family is a major source of reactive oxygen species (ROS) [4]. The most extensively studied ROS include hydroxyl radical, superoxide anion, and $\mathrm{H}_{2} \mathrm{O}_{2}$ [5]. Among seven Nox families, Nox4 is the most abundant in the human kidney, predominantly in the proximal tubule [6]. The sole function of Nox4 is to produce $\mathrm{H}_{2} \mathrm{O}_{2}$ [7].

Advanced oxidation protein product (AOPP), formed mainly by chlorinated oxidants resulting from myeloperoxidase activity, is produced under oxidative conditions and recognized as a novel marker of oxidative damage [8]. Not only are AOPPs products of chronic oxidative stress but also they could trigger oxidative stress and further stimulate ROS generation, leading to an unstoppable positive-feedback loop [9]. AOPPs activate the intrarenal renin-angiotensin system (RAS) through mechanisms involving CD36, protein kinase $\mathrm{C}$ alpha, Nox, and nuclear factor- $\kappa \mathrm{B}$ signaling, leading to 
intrinsic renal cells, including endothelial cells, podocytes, and tubular epithelial cells, and excessive production of intracellular superoxide upon stimulation [10-13]. However, the molecular mechanisms underlying the pharmacological actions of AOPP remain unclear.

In 2002, Nguyen and colleagues cloned full-length (pro)renin receptor (fPRR), which directly bound to renin and prorenin preferentially, thereby triggering renal RAS $[14,15]$. fPRR belongs to the type I transmembrane receptor family, characterized by containing an interesting $28 \mathrm{kDa}$ soluble PRR (sPRR) and generated by site-1 protease (S1P) $[16,17]$. Intensive clinical studies have proven that sPRR levels are significantly upregulated in various diseases and disease models, such as severe heart failure, hemodialysis maintenance, and primary aldosteronism, thus suggesting the value of sPRR as a biomarker [18-21]. sPRR is hypothesized to bind to specific ligands and receptors and mediate many signal transduction pathways [22-30]. For example, S1P-derived SPRR through the activation of intrarenal RAS and ENaC mediated Ang II-induced hypertension [26]. It targeted vasopressin receptor 2 to enhance urineconcentrating capability [29]. In addition, S1P-derived sPRR promoted inflammation via the Nox $4 / N F-\kappa B$ pathway and upregulated proinflammatory cytokines (IL-6 and IL-8) and adhesion molecules (vascular cell adhesion protein 1 (VCAM-1)) [31]. S1P-derived sPRR was also shown to promote fibronectin via the activation of the $\mathrm{AKT} / \beta$-catenin/ snail pathway in HK-2 cells [28].

This study investigated the role of S1P-derived SPRR in AOPP-elicited oxidative accentuation injury in renal tubule cells and its potential signaling pathways.

\section{Materials and Methods}

2.1. Reagents. $\alpha 1$-Antitrypsin Portland ( $\alpha 1$-PDX) and furin inhibitor I (decanoyl-Arg-Val-Lys-Arg-chloromethylketone) were from Calbiochem. The ADAM19 inhibitor GM6001 $\left(\mathrm{C}_{20} \mathrm{H}_{28} \mathrm{~N}_{4} \mathrm{O}_{4}\right)$ was from MedChemExpress. The S1P inhibitor PF429242 $\left(\mathrm{C}_{25} \mathrm{H}_{35} \mathrm{~N}_{3} \mathrm{O}_{2}\right)$ was from AdooQ Biosciences. Human serum albumin (HSA) was from Sigma. PRO20 ( $\mathrm{L}^{1}$ PTDTASFGRILLKKMPSVR ${ }^{20}$ ) was synthesized by Shenzhen Huada Gene Co., Ltd. sPRR-His was manufactured by Qinghong Biotech.

2.2. Preparation of AOPP-HSA. Fatty acid-free HSA solution $(30 \mathrm{mg} / \mathrm{ml})$ was incubated with $100 \mathrm{mM} \mathrm{HOCl}$ (Fluke) at room temperature for $30 \mathrm{~min}$ without free amino acids, free carbohydrates, and lipids. Then, the preparation was dialyzed against phosphate buffer solution (PBS, Life Technologies) to remove free hypochlorous acid at $4^{\circ} \mathrm{C}$ overnight.

2.3. Cell Culture and Cell Culture Reagents. A human kidney proximal tubule epithelial cell line (HK-2) was purchased from Procell Life Science Co., Ltd. The HK-2 cells were cultured in Dulbecco's modified Eagle's medium/F12 medium containing $10 \%$ fetal bovine serum, penicillin $(200 \mathrm{U} / \mathrm{ml})$, and streptomycin $(200 \mathrm{mg} / \mathrm{ml}$, all obtained from Procell Life Science) at $37^{\circ} \mathrm{C}$ in a $5 \% \mathrm{CO}_{2}$ atmosphere. After $12 \mathrm{~h}$ of serum starvation, the cells were
TABle 1: Primer sequences for qRT-PCR analysis.

\begin{tabular}{lc}
\hline Primer name & Primer sequence \\
\hline GAPDH F & GGAGCGAGATCCCTCCAAAAT \\
GAPDH R & GGCTGTTGTCATACTTCTCATGG \\
AGT F & ACAATGAGAGTACCTGTGAGCA \\
AGT R & TCTTGGCCTGAATTGGAGCAG \\
AT1R F & ATTTAGCACTGGCTGACTTATGC \\
AT1R R & CAGCGGTATTCCATAGCTGTG \\
ACE F & GGAGGAATATGACCGGACATCC \\
ACE R & TGGTTGGCTATTTGCATGTTCTT \\
S1P F & ACCTCGAAACAATCCATCCAGT \\
S1P R & ACTTGAGGGAACGAAAGACTTTT \\
ICAM-1 F & ATGCCCAGACATCTGTGTCC \\
ICAM-1 R & GGGGTCTCTATGCCCAACAA \\
TNF- $\alpha$ F & CCTCTCTCTAATCAGCCCTCTG \\
TNF- $\alpha$ R & GAGGACCTGGGAGTAGATGAG \\
Nox-1 F & TTGTTTGGTTAGGGCTGAATGT \\
Nox-1 R & GCCAATGTTGACCCAAGGATTTT \\
Nox-2 F & ACCGGGTTTATGATATTCCACCT \\
Nox-2 R & GATTTCGACAGACTGGCAAGA \\
Nox-3 F & ACCGTGGAGGAGGCAATTAGA \\
Nox-3 R & TGGTTGCATTAACAGCTATCCC \\
Nox-4 F & CAGATGTTGGGGCTAGGATTG \\
Nox-4 R & CAGAGTCGGCACATGGGTA \\
Nox-5 F & \\
Nox-5 R & fPRR F
\end{tabular}

treated with either $100 \mu \mathrm{g} / \mathrm{ml}$ AOPP, $100 \mu \mathrm{g} / \mathrm{ml} \mathrm{HSA}, 4 \mu \mathrm{M}$ PRO20 [32], $50 \mu \mathrm{M}$ furin inhibitor I, $5 \mu \mathrm{M} \alpha 1$-PDX, $25 \mu \mathrm{M}$ GM6001, $40 \mu \mathrm{M}$ PF429242, or $50 \mathrm{nM}$ recombinant sPRR (sPRR-His) for $1 \mathrm{~h}$, or they were transfected with either fPRR siRNA (Origene), Nox4 siRNA (Ambion), or S1P siRNA (Origene) for $24 \mathrm{~h}$. These cells were then used to analyze fPRR/sPRR protein expression, while the cell medium for sPRR (Immuno-Biological Laboratories) and Ang II (Enzo Life Sciences) concentrations was analyzed by using ELISA kits in accordance with the manufacturer's instructions. Cell content was normalized to protein content and expressed as $\mathrm{pg} / \mathrm{mg}$ protein.

2.4. Small Interfering RNA (siRNA). RNA interference was implemented using siRNA to silence endogenous fPRR, S1P, and Nox4. HK-2 cells were grown to $70 \%-80 \%$ confluence in six-well culture plates and transfected with fPRR, S1P, Nox4 siRNAs, or control nontargeting siRNA. After the HK-2 cells were transfected with siRNA for $24 \mathrm{~h}$ with HiPerFect Transfection Reagent (Qiagen), the supernatant was removed with siRNA and AOPP was added for a further $24 \mathrm{~h}$. Then, $48 \mathrm{~h}$ after transfection, the cells were harvested and subjected to RNA analysis. For Western blotting analysis, the HK-2 cells were transfected with siRNA for $24 \mathrm{~h}$, the 


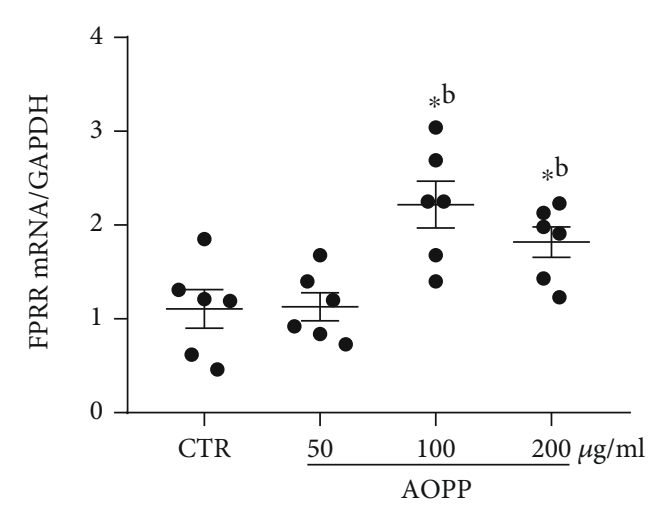

(a)

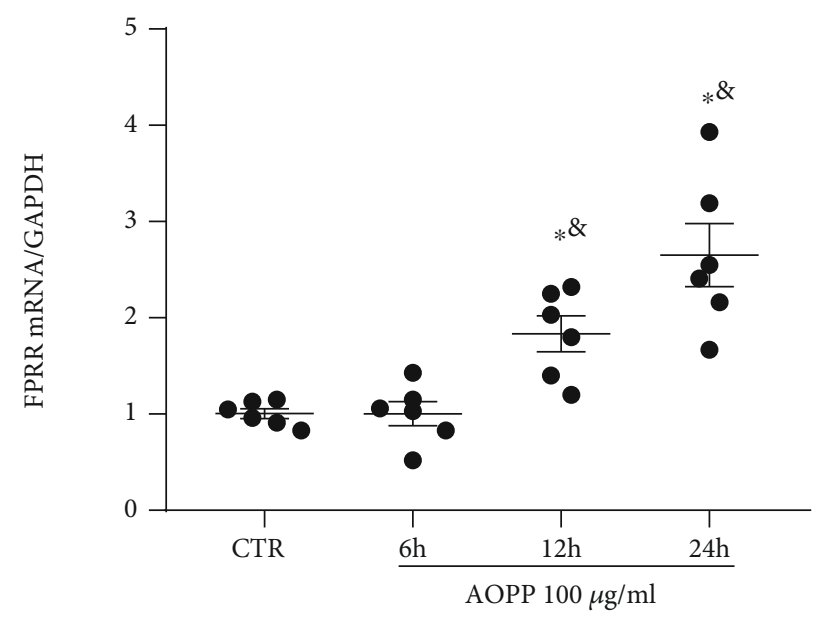

(c)

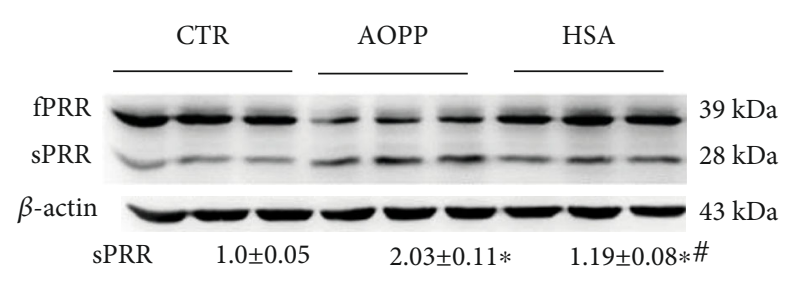

(e)

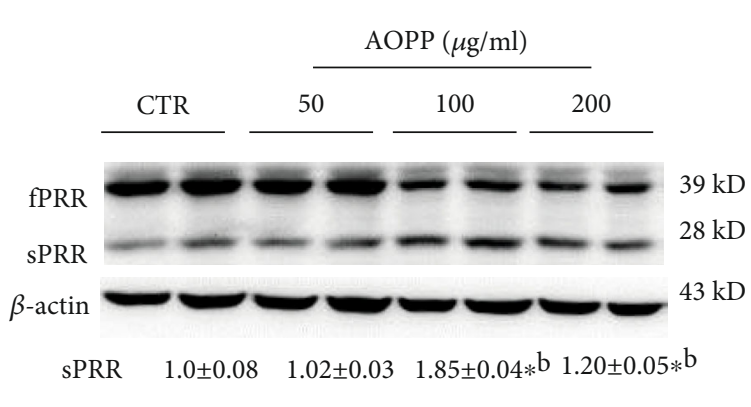

(b)

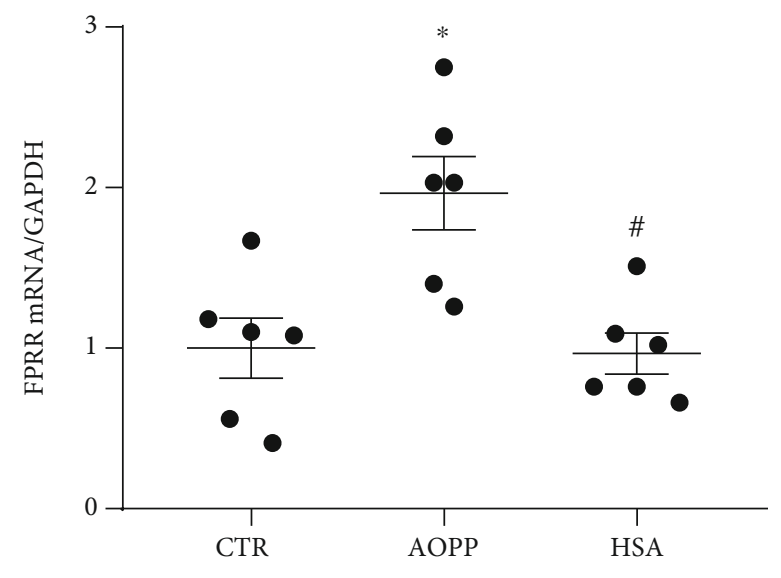

(d)

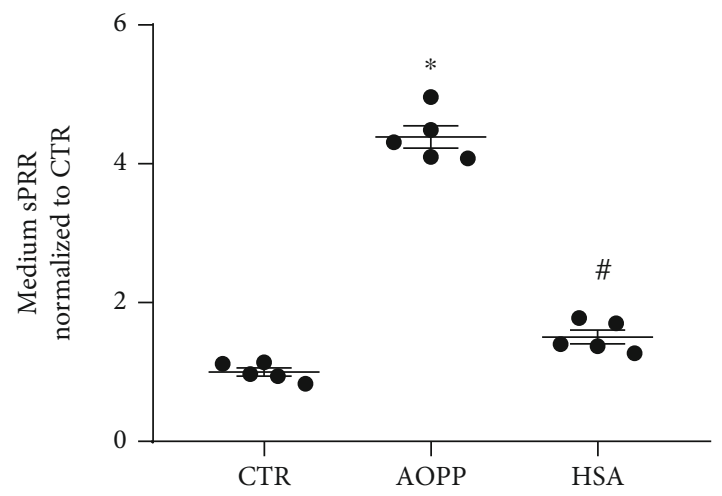

(f)

FIGURE 1: AOPP treatment activated fPRR cleavage to generate sPRR. HK-2 cells were incubated with various concentrations of AOPP (50, 100 , and $200 \mu \mathrm{g} / \mathrm{ml}$ ) for $24 \mathrm{~h}$, and fPRR mRNA levels were determined by qRT-PCR (a) and Western blotting (b, representative picture). With the use of AOPP $(100 \mu \mathrm{g} / \mathrm{ml})$ for the indicated time period $(6,12$, and $24 \mathrm{~h})$, the expression of fPRR mRNA levels was determined by qRT-PCR (c). Values were normalized to GAPDH for qRT-PCR. $\beta$-Actin was used as a loading control ( $n=6$ per group). ${ }^{*} p<0.05$ versus CTR; ${ }^{\mathrm{b}} p<0.05$ versus $50 \mu \mathrm{g} / \mathrm{ml} \mathrm{AOPP}$; and ${ }^{\&} p<0.05$ versus $6 \mathrm{~h}$ AOPP. In separate experiments, HK-2 cells were treated up to $24 \mathrm{~h}$ with control (CTR), AOPP $(100 \mu \mathrm{g} / \mathrm{ml})$, or unmodified HSA $(100 \mu \mathrm{g} / \mathrm{ml})$ for $24 \mathrm{~h}$. (d) qRT-PCR for fPRR mRNA expression. Values were normalized to the housekeeping gene GAPDH ( $n=6$ per group). (e) fPRR/sPRR protein expression was analyzed by Western blotting (e, representative figure) and normalized to $\beta$-actin $(n=6$ per group). (f) Supernatants from cells were used for the measurement of sPRR protein by ELISA and normalized for protein content $\left(n=5\right.$ per group). ${ }^{*} p<0.05$ versus CTR; ${ }^{*} p<0.05$ versus $100 \mu \mathrm{g} / \mathrm{ml}$ AOPP. Data are mean \pm SE; $n$ is the sample size per group. All experiments were repeated independently twice with similar results, and all attempts of replication were successful. 


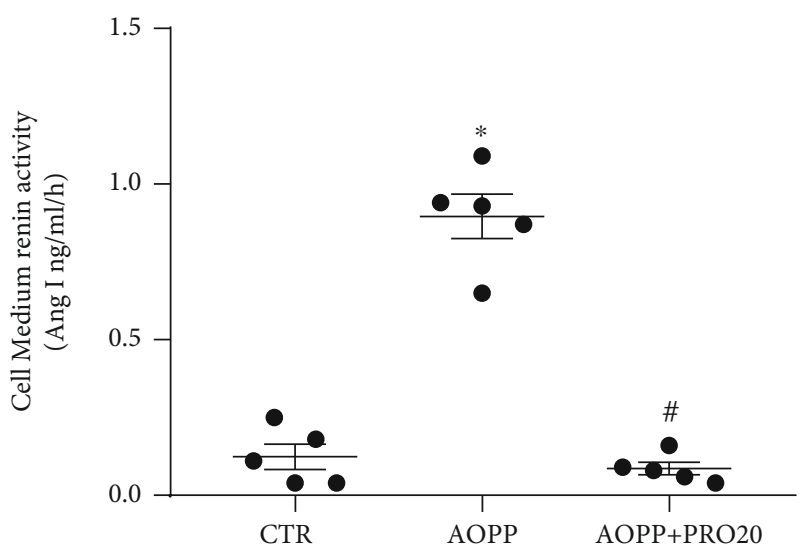

(a)

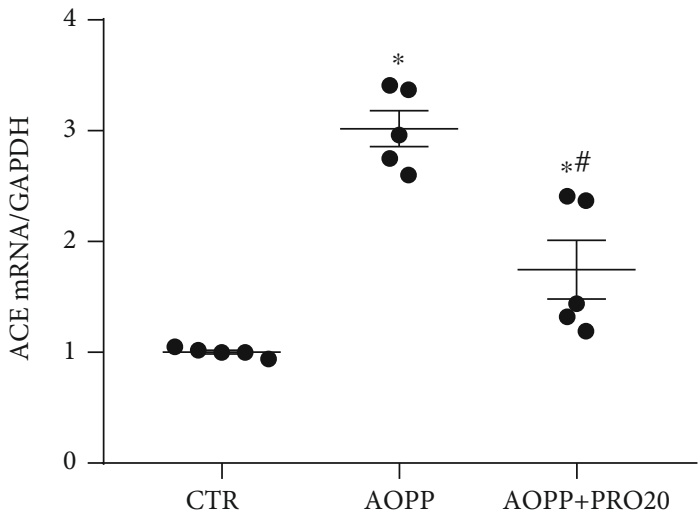

(c)

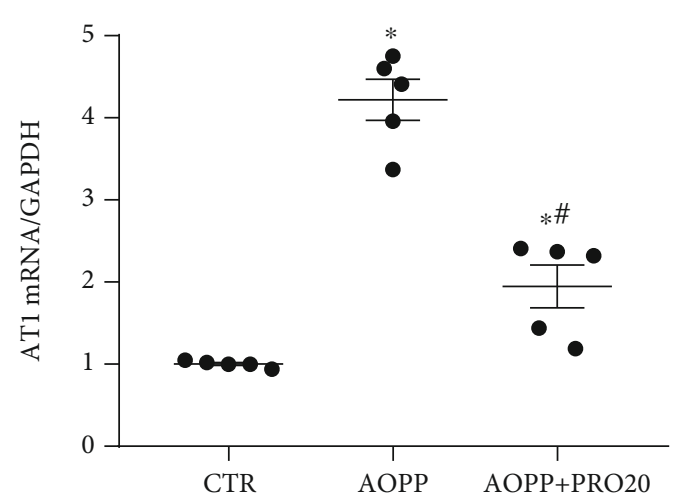

(e)

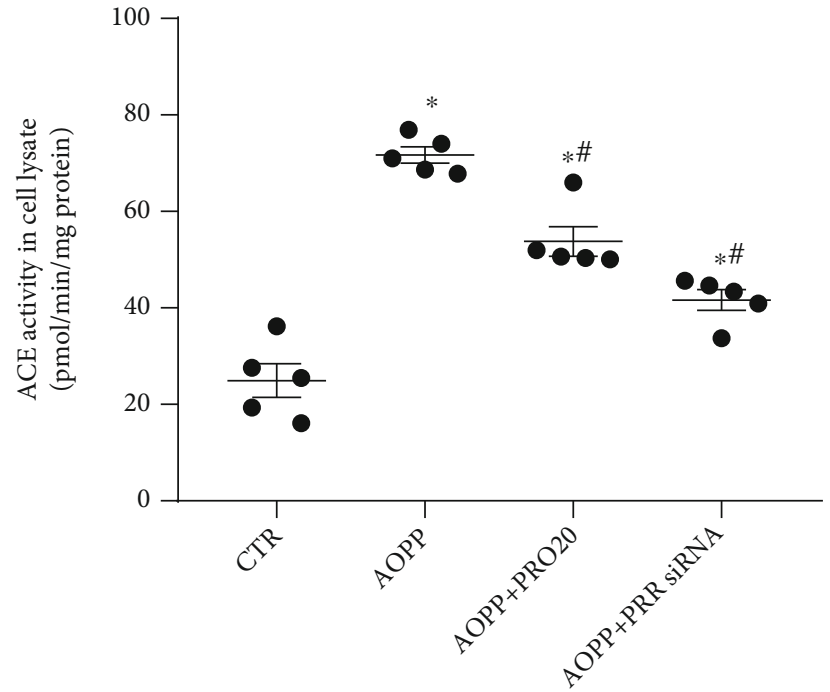

(b)

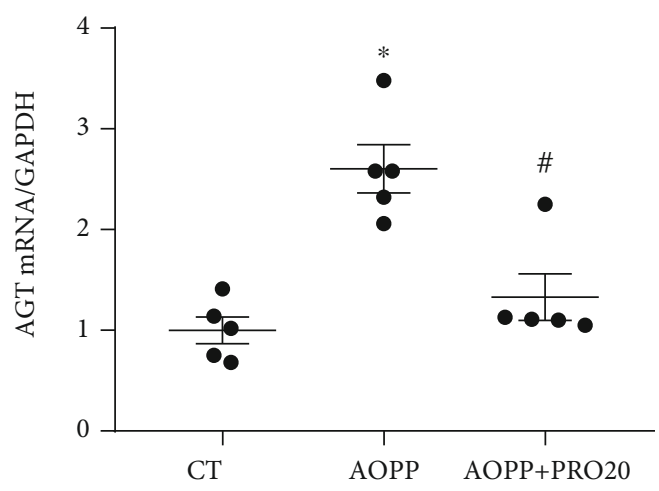

(d)

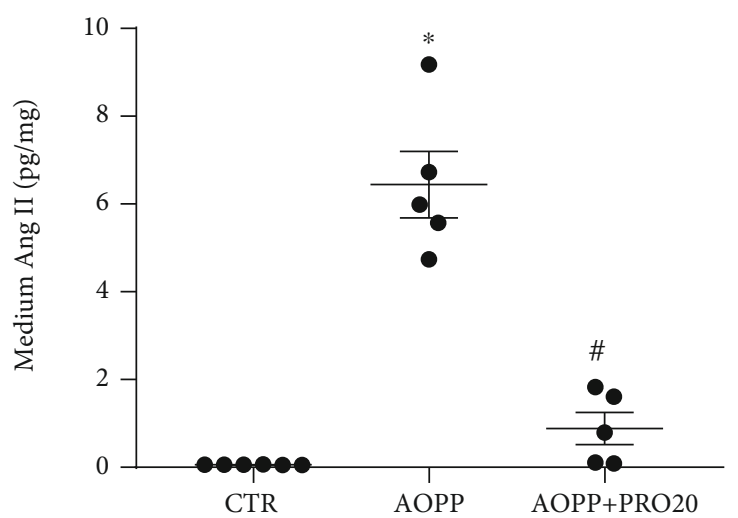

(f)

Figure 2: Continued. 


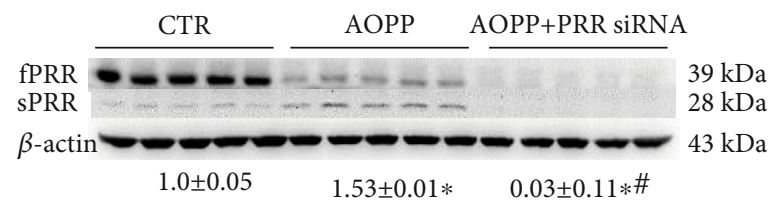

(g)

Figure 2: AOPP treatment-activated intrarenal RAS components were mainly mediated by fPRR in HK-2 cells. HK-2 cells were treated up to $24 \mathrm{~h}$ with CTR, AOPP $(100 \mu \mathrm{g} / \mathrm{ml})$ alone, or AOPP in combination with PRO20 $(4 \mu \mathrm{M})$ or fPRR siRNA. (a) ELISA detection of cell medium renin activity. (b) ACE activity in cell lysates. (c-e) qRT-PCR analysis of ACE, AGT, and AT1R mRNA expression in cell lysates and normalization by GAPDH ( $n=5$ per group). (f) ELISA analysis of medium Ang II. (g) fPRR and sPRR protein expression levels were detected by Western blotting. ${ }^{*} p<0.05$ versus CTR; ${ }^{*} p<0.05$ versus AOPP. Data are mean \pm SE; $n$ is the sample size per group. In all transfection experiments, the sample CTR, AOPP alone, or AOPP with PRO20 indicated the transfected cells with control nontargeting siRNA. All experiments were repeated independently twice with similar results, and all attempts of replication were successful.

supernatant was removed with siRNA, medium was changed to normal growth medium for additional $24 \mathrm{~h}$, and AOPP was added for a further $24 \mathrm{~h}$. The transfected cells were collected $72 \mathrm{~h}$ after transfection with Nox4 siRNA, and the protein concentrations of sPRR and $\mathrm{H}_{2} \mathrm{O}_{2}$ in the medium were examined by ELISA $72 \mathrm{~h}$ posttransfection.

2.5. Measurement of TBARS and $\mathrm{H}_{2} \mathrm{O}_{2}$. The level of malondialdehyde (MDA) in HK-2 cells was tested using a commercially available kit (TBARS Assay Kit, Cayman Chemical Company) in accordance with the manufacturer's protocol [33]. Lysate $\mathrm{H}_{2} \mathrm{O}_{2}$ was measured using a ROS-Glo $\mathrm{H}_{2} \mathrm{O}_{2}$ Assay kit (Promega), following the manufacturer's instructions.

2.6. Measurement of Medium Renin Activity. At the end of treatment, cell media were harvested for subsequent analysis. Medium renin activity was defined by the concentrations of Ang I release at $37^{\circ} \mathrm{C}$ minus Ang I release at $4^{\circ} \mathrm{C}$ (Ang I Peptide Enzyme Immunoassay, Peninsula Laboratories International). The values were corrected for total protein concentration and expressed as ng/ml/h Ang I.

2.7. Measurement of Cell Lysate ACE Activity. Cell lysates were prepared to measure ACE activity [10]. In brief, an aliquot sample was incubated with synthetic ACE-specific substrate hippuryl-histidyl-leucine. The liberated His-Leu was converted into a fluorescent product by incubating with o-phthaldialdehyde. Then, the fluorescence of samples was detected with a MRX microplate reader (Dynex Technologies) at an emission wavelength of $495 \mathrm{~nm}$ upon excitation at $365 \mathrm{~nm}$.

2.8. Western Blotting. Protein extraction and Western blotting analysis were performed as previously described [16]. Cells were washed three times with cold PBS and lysed with RIPA lysis buffer (Beyotime) with added AEBSF (Beyotime) on ice. The homogenized cells were centrifuged for $10 \mathrm{~min}$ at $12,000 \mathrm{~g}$ at $4^{\circ} \mathrm{C}$. Protein samples $(40 \mu \mathrm{g})$ were mixed with $5 \times$ loading buffer (Beyotime Institute of Biotechnology). The mixture was incubated in a metal bath at $100^{\circ} \mathrm{C}$ for $10 \mathrm{~min}$. Proteins $(30 \mu \mathrm{g})$ were resolved by SDS-polyacrylamide gel electrophoresis (SDS-PAGE) and transferred onto nitrocellulose (Amersham Pharmacia Biotech) membranes for Western blotting. After being transferred, nonspecific binding was blocked with $5 \%$ nonfat dry milk in $1 \times$ Tris-buffered saline-Tween-20 (TBST) at RT for $1 \mathrm{~h}$. Subsequently, the membranes were incubated with primary antibodies (antiPRR antibody, Sigma; anti-S1P antibody, Abcam; antiNox4, Abcam; and anti- $\beta$-actin, Beyotime) overnight at $4^{\circ} \mathrm{C}$. After incubation, the membranes were washed again three times with TBST at RT (7 min per wash) and incubated with secondary antibodies (goat anti-rabbit, $1: 2,500$ dilution in TBST; goat anti-mouse 1:5,000 dilution in TBST; Beijing Zhongshan Jinqiao Biotechnology) for $1 \mathrm{~h}$. Protein bands were visualized using the ECL detection kit (Beyotime). Densitometric analysis of each band was performed on ImagePro Plus 6.0.

2.9. Quantitative Real-Time Reverse Transcription-PCR (qRT-PCR). RNA protocols and qRT-PCR were carried out as previously described [34]. Gene expression was normalized to GAPDH. The cells were snap frozen in the TRIzol reagent (CWBio). All samples were treated with DNase digestion during RNA purification by using the RNaseFree DNase kit (Kirgen). RNA was converted to cDNA by using the High-Capacity cDNA Reverse Transcription Kit (Qiagen). The sequences of the primers (Shanghai Sangon Company) are listed in Table 1. qRT-PCR was performed using SYBR Green Master Mix (Toyobo) and a LightCycler 480 Real-Time PCR System (Roche). The PCR program was as follows: $95^{\circ} \mathrm{C}$ for $10 \mathrm{~min} ; 40$ cycles of $95^{\circ} \mathrm{C}$ for $5 \mathrm{~s}$, $55^{\circ} \mathrm{C}$ for $10 \mathrm{~s}$, and $72^{\circ} \mathrm{C}$ for $15 \mathrm{~s}$; and $72^{\circ} \mathrm{C}$ for $7 \mathrm{~min}$. All qRT-PCR reactions were carried out in duplicate.

2.10. Statistical Analysis. Summary data are presented as means \pm SE. Student's $t$-test and the Kruskal-Wallis nonparametric statistical test followed by Dunn's multiple comparison test were performed using GraphPad Prism 6 (GraphPad Software) for statistical analysis. All data points were included in the statistical analyses. The Shapiro-Wilk test was used to confirm the Gaussian distributions of raw data. A $p$ value lower than $0.05(p<0.05)$ was considered statistically significant.

\section{Results}

3.1. AOPP Induced Cleavage of PPRR, but Unmodified HSA of the Same Concentration Had No Effect in HK-2 Cells. As 


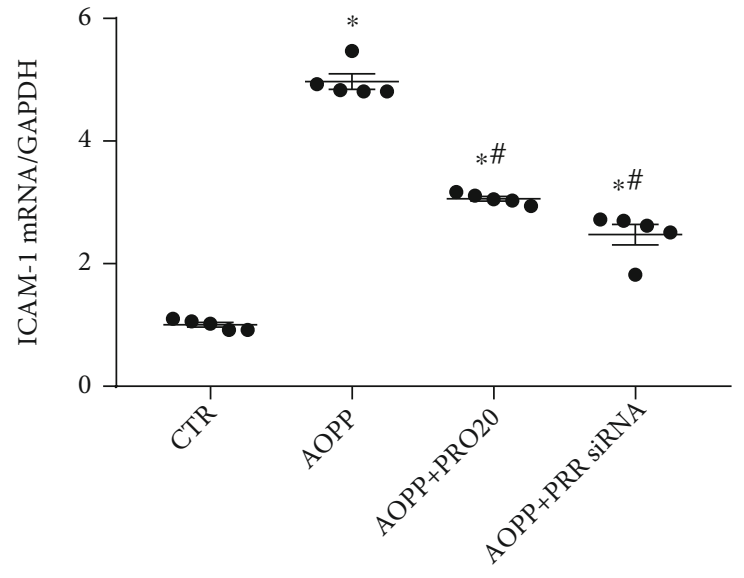

(a)

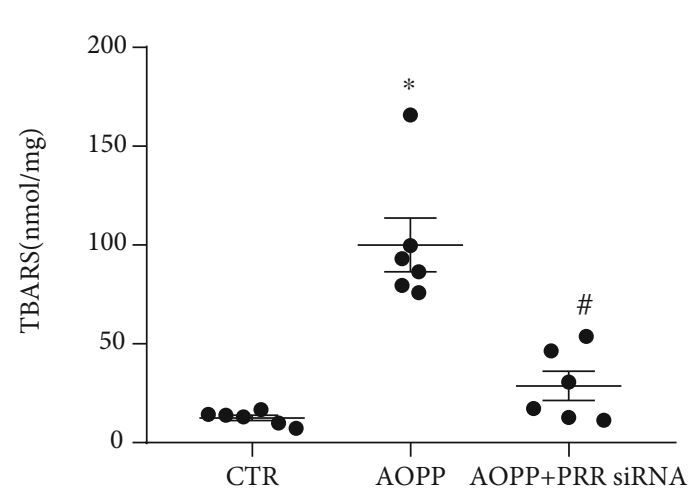

(c)

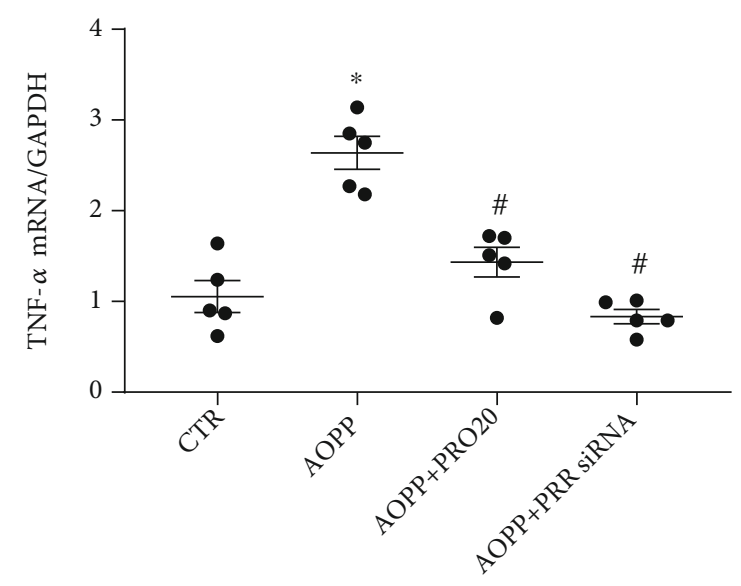

(b)

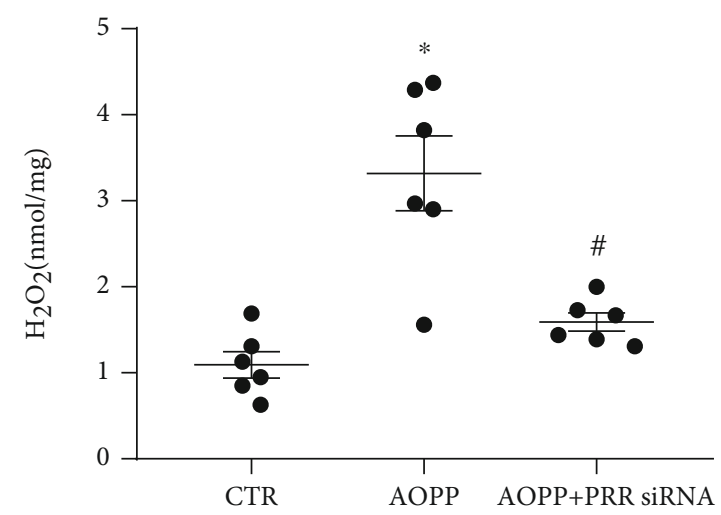

(d)

FIGURE 3: AOPP treatment-induced ICAM-1, TNF- $\alpha$, TBARS, and $\mathrm{H}_{2} \mathrm{O}_{2}$ upregulated expression levels were mainly mediated by fPRR in HK-2 cells. The HK-2 cells were treated up to $24 \mathrm{~h}$ with CTR, AOPP $(100 \mu \mathrm{g} / \mathrm{ml}), \mathrm{AOPP}+\mathrm{PRO} 20$, and/or AOPP+fPRR siRNA. (a, b) qRT-PCR for ICAM-1 (a) and TNF- $\alpha$ (b) mRNA expression with normalization by GAPDH ( $n=5$ per group). (c) Cell lysate TBARS. The TBARS levels were standardized by the protein content of each sample ( $n=6$ per group). (d) Cell lysate $\mathrm{H}_{2} \mathrm{O}_{2}$. ELISA data of cell lysate samples normalized with protein concentrations $\left(n=6\right.$ per group). ${ }^{*} p<0.05$ versus CTR; ${ }^{*} p<0.05$ versus AOPP. Data are mean $\pm \mathrm{SE}$; $n$ is the sample size per group. In all transfection experiments, the sample CTR, AOPP alone, or AOPP with PRO20 indicated the transfected cells with control nontargeting siRNA. All experiments were repeated independently twice with similar results, and all attempts of replication were successful.

shown in Figure 1, HK-2 cells were cultured for $24 \mathrm{~h}$ with different final concentrations of AOPP-HSA $(100,200 \mu \mathrm{g} / \mathrm{ml})$. In the medium, the induced $\mathrm{fPRR}$ was cleaved to generate sPRR, as analyzed by qRT-PCR detection of the increased fPRR mRNA levels and Western blotting detection of the augmented sPRR protein expression; sPRR reached the peak at $100 \mu \mathrm{g} / \mathrm{ml}$ AOPP (Figures 1(a) and 1(b)). In addition, AOPP-HSA $(100 \mu \mathrm{g} / \mathrm{ml})$ upregulated fPRR mRNA expression levels in a time-dependent manner (Figure 1(c)). In order to eliminate the interference of unmodified albumin, exposure of HK-2 cells to AOPP-HSA $(100 \mu \mathrm{g} / \mathrm{ml})$ significantly induced fPRR cleavage events, whereas HSA under the same protein concentration has had no effect. As shown in Figure $1(\mathrm{~d})$, AOPP-HSA $(100 \mu \mathrm{g} / \mathrm{ml})$ upregulated the expression of fPRR mRNA levels, whereas HSA $(100 \mu \mathrm{g} / \mathrm{ml})$ had no effect. As shown in Figure 1(e), AOPP-HSA $(100 \mu \mathrm{g} / \mathrm{ml})$ upregulated the expression of sPRR protein expression, whereas HSA $(100 \mu \mathrm{g} / \mathrm{ml})$ had no effect. As shown in Figure 1(f), AOPP-HSA $(100 \mu \mathrm{g} / \mathrm{ml})$ significantly promoted the secretion of SPRR by more than four times in the medium, whereas HSA $(100 \mu \mathrm{g} / \mathrm{ml})$ had no effect.

These results showed that AOPP-induced PPRR cleavage produced sPRR in HK-2 cells.

3.2. AOPP Induced Activation of the RAS System, and Inhibition of fPRR Significantly Inhibited It. Previous literature reported that AOPP upregulated the expression of nearly all members of RAS in cultured proximal tubule epithelial cells [10]. Therefore, the role of fPRR in AOPPinduced RAS activation was examined.

Figure 2(a) shows that the cell-medium renin activity significantly increased in the AOPP $(100 \mu \mathrm{g} / \mathrm{ml})$ group, while it was nearly normalized in the AOPP+PRO20 group. The ACE activity in cell lysates was elevated more than 3.5fold in the AOPP group compared with the control group (CTR), and this elevation was significantly repressed in the AOPP+PRO20 group and AOPP+fPRR siRNA group $(p<0.05$, Figure 2(b)). Similar trends were obtained by 


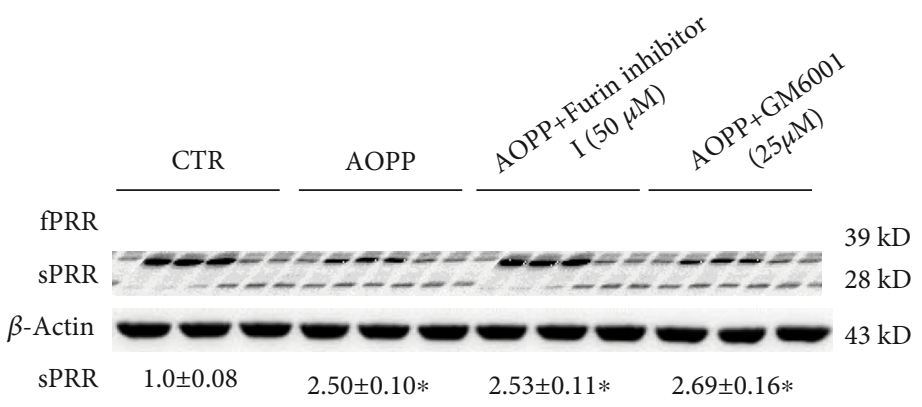

(a)

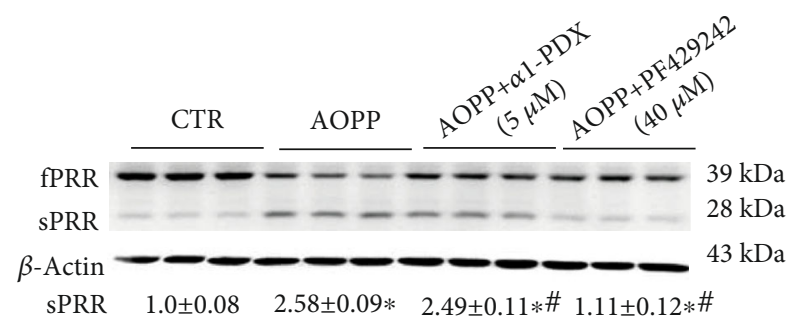

(c)

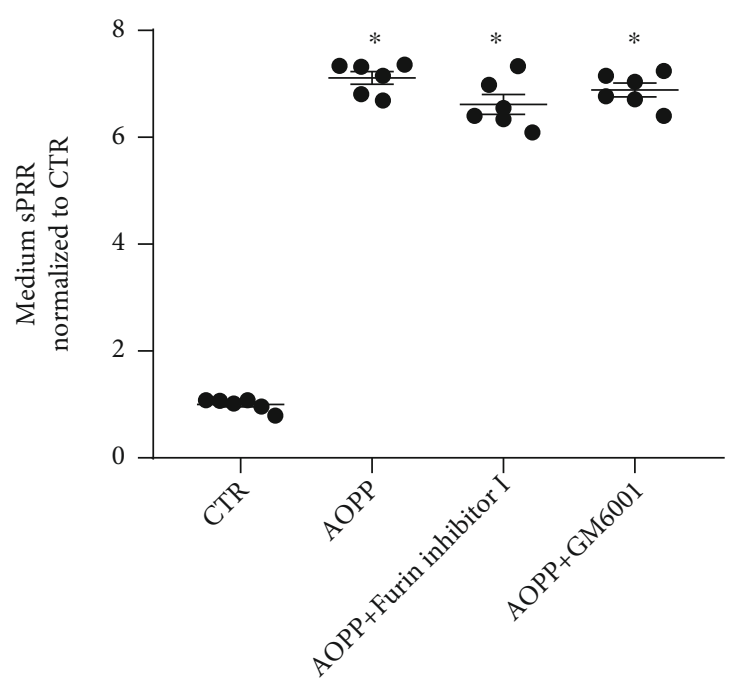

(b)

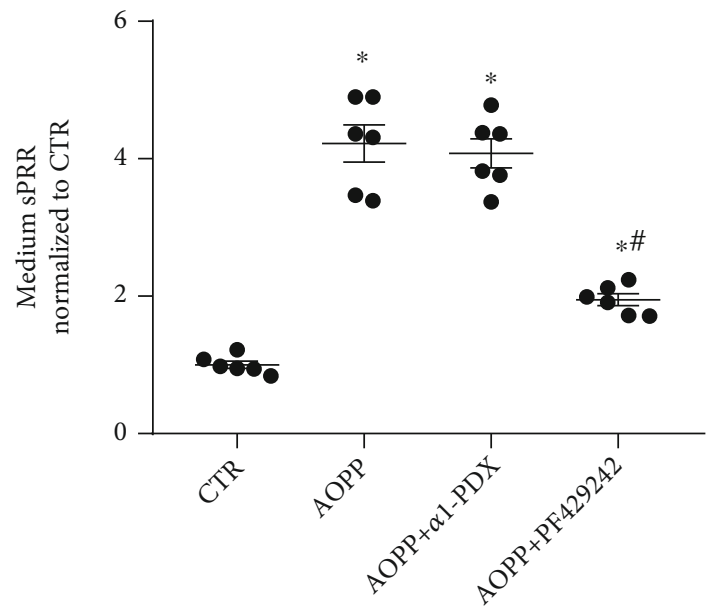

(d)

FIgURE 4: Furin inhibitor I and ADAM inhibitor GM6001 failed to affect fPRR cleavage, but the S1P inhibitor PF429242 significantly inhibited fPRR cleavage events induced by AOPP in HK-2 cells. The HK-2 cells were pretreated with furin inhibitor I (50 $\mu \mathrm{M})$, GM6001 $(25 \mu \mathrm{M}), \alpha 1$-PDX $(5 \mu \mathrm{M})$, or PF429242 $(40 \mu \mathrm{M})$ for $1 \mathrm{~h}$ and then incubated with $100 \mu \mathrm{g} / \mathrm{ml}$ AOPP for $24 \mathrm{~h}$. fPRR and sPRR protein expression levels were detected by Western blotting (a, representative picture) and normalized to $\beta$-actin. Densitometry analysis is shown below Western blotting ( $n=6$ per group). (b) sPRR protein concentration in culture medium was determined by ELISA, and the values were normalized to protein content ( $n=6$ per group). ${ }^{*} p<0.05$ versus CTR; ${ }^{\#} p<0.05$ versus AOPP. Data are mean \pm SE; $n$ is the sample size per group. All experiments were repeated independently twice with similar results, and all attempts of replication were successful.

qRT-PCR analysis of ACE, AGT, and AT1R $(p<0.05$, Figures 2(c)-2(e)). The cell culture medium expressing Ang II was significantly higher in the AOPP group than in the CTR group $(p<0.05)$, and this expression was also blocked by fPRR siRNA treatment $(p<0.05$, Figure $2(\mathrm{f}))$. Western blotting was then performed to test the silencing effect of siRNA on the expression levels of PRR. Figure 2(g) shows reduced fPRR and sPRR protein expression levels following PRR siRNA treatment.

These results suggested that AOPP may lead to proximal tubule cell injury through the fPRR-mediated activation of renal RAS.

3.3. AOPP Induced Activation of Renal Oxidative Stress, and Inhibition of fPRR Significantly Inhibited It. To the best of the authors' knowledge, compelling evidence revealed the close association between increased AOPP and oxidative stress [35]. Therefore, intercellular adhesion molecule 1 (ICAM-1), TNF- $\alpha$, TBARS, $\mathrm{H}_{2} \mathrm{O}_{2}$, and the markers for oxidative stress were examined in the present study. Cell lysates' ICAM- 1 and TNF- $\alpha$ mRNA levels were significantly higher in the AOPP group than in the control group, and this expression was also blocked in the $\mathrm{AOPP}+\mathrm{PRO} 20$ and AOPP +fPRR siRNA groups $(p<0.05$, Figures $3(a)$ and $3(\mathrm{~b}))$. Similar results were acquired by ELISA analysis of TBARS and $\mathrm{H}_{2} \mathrm{O}_{2}(p<0.05$, Figures 3(c) and 3(d)).

3.4. AOPP Induced fPRR Cleavage to Produce $S P R R$, Which Is Mainly Mediated by S1P. As shown in Figures 4(a) and 4(b), furin inhibitor I could inhibit the cleavage of fPRR, but it did 


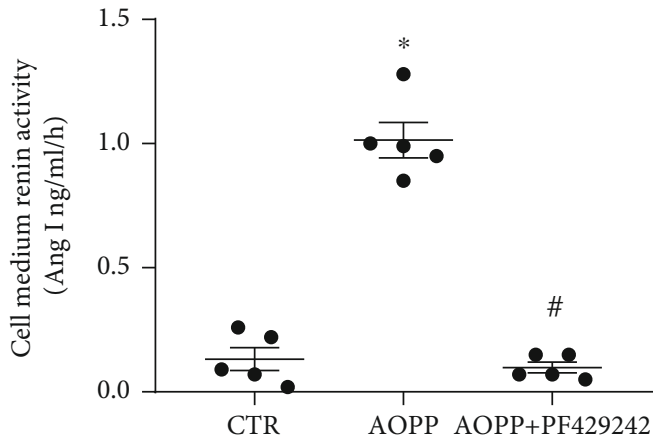

(a)

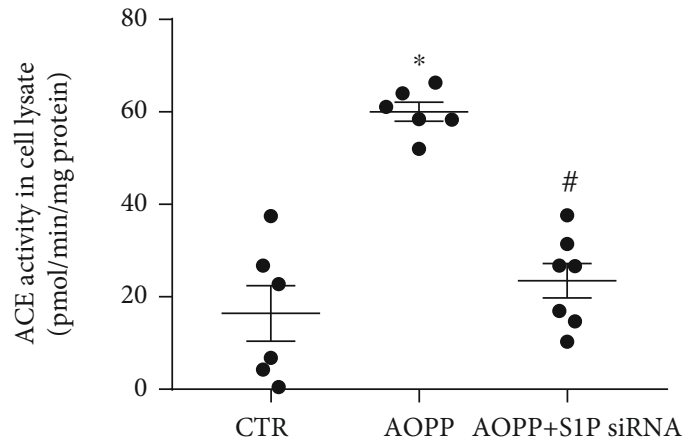

(b)

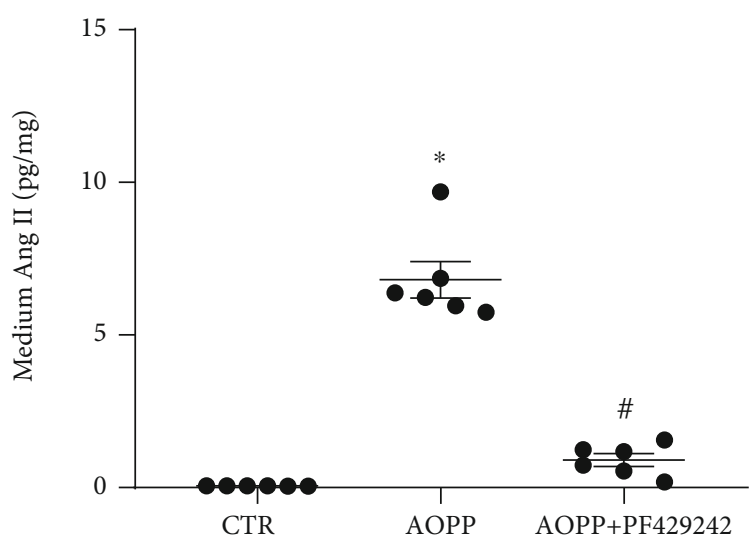

(d)

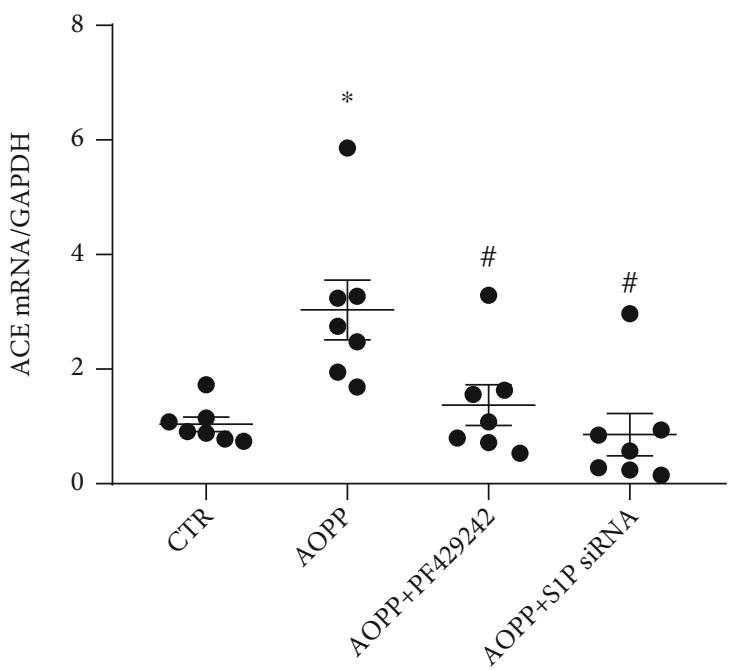

(f)

Figure 5: Continued. 


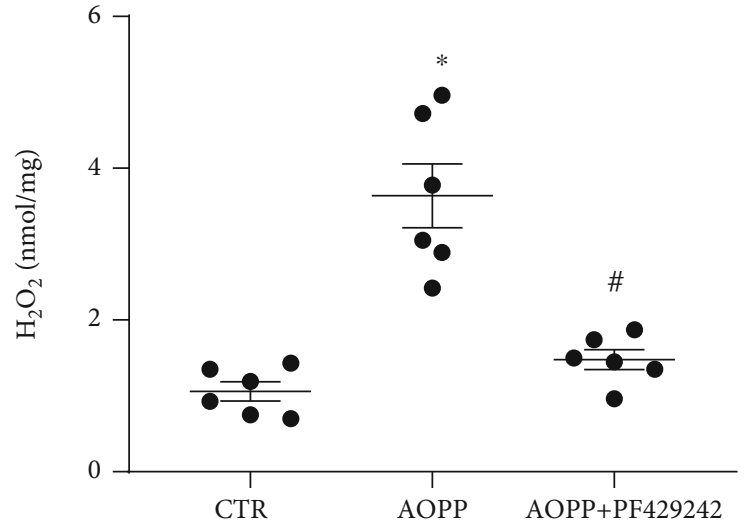

(g)

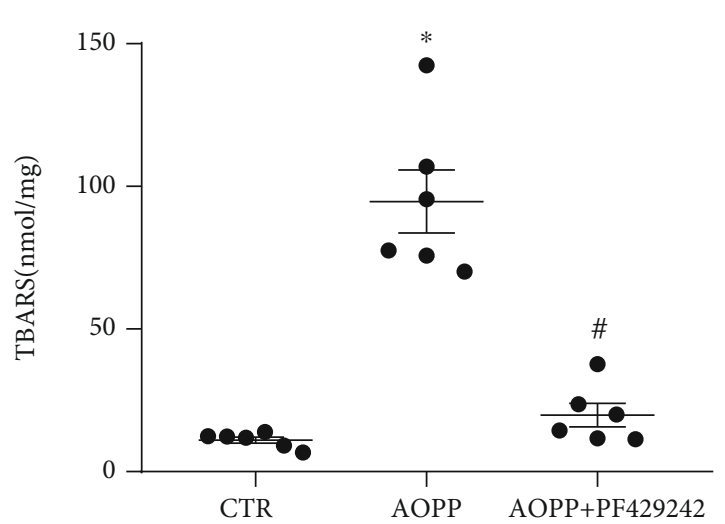

(h)

FIGURE 5: AOPP treatment-induced RAS component activation was mediated by S1P-derived sPRR in HK-2 cells. The HK-2 cells were treated up to $24 \mathrm{~h}$ with CTR, AOPP $(100 \mu \mathrm{g} / \mathrm{ml})$ alone, or AOPP in combination with PF429242 $(40 \mu \mathrm{M})$ or transfected with S1P siRNA. (a) ELISA detection of cell medium renin activity. (b) ACE activity in cell lysate by the fluorometric method. (c) S1P protein expression levels were analyzed by Western blotting. (d) ELISA analysis of medium Ang II. (e, f) qRT-PCR for AT1R (e) and ACE (f) mRNA expression with normalization by GAPDH ( $n=5$ per group). (g) Cell lysate $\mathrm{H}_{2} \mathrm{O}_{2}$. The ELISA data of the cell lysate sample were normalized with protein concentrations. (h) Cell lysate TBARS. The TBARS levels were standardized by the protein content of each sample. ${ }^{*} p<0.05$ versus CTR; ${ }^{*} p<0.05$ versus AOPP. Data are mean \pm SE; $n=5-6$ per group, where $n$ is the sample size per group. In all transfection experiments, the sample CTR, AOPP alone, or AOPP with PF429242 indicated the transfected cells with control nontargeting siRNA. All experiments were repeated independently twice with similar results, and all attempts of replication were successful.

not affect the production of sPRR, and GM6001 completely did not affect the cleavage events of fPRR, according to Western blotting and ELISA. As shown in Figures 4(c) and $4(\mathrm{~d})$, another furin inhibitor, $\alpha 1-\mathrm{PDX}$, could also inhibit the cleavage of PPRR, but it did not affect the production of sPRR. Further, furin inhibitor I treatment-induced PRR upregulation was modest at the mRNA level compared with AOPP treatment $(p<0.05$, Supplementary Figure 1A). This finding may explain the reason for furin inhibitors inhibiting the cleavage of fPRR. However, the S1P inhibitor PF429242 significantly inhibited the cleavage of fPRR to produce sPRR, and the contents of sPRR in the medium were significantly reduced by more than $50 \%$ compared with those in the AOPP group $(p<0.05)$.

3.5. AOPP Induced Activation of Renal Local RAS and Oxidative Stress, and Inhibition of S1P-Derived sPRR Significantly Inhibited This Activation. As shown in Figures 5(a), 5(b), and 5(d), medium renin activity, lysate ACE activity, and Ang II were all significantly higher in the AOPP group than in the CTR group $(p<0.05)$, and expression was blocked by PF429242 or S1P siRNA treatment $(p<0.05)$. The protein expression after S1P siRNA knockdown was evaluated by Western blotting analysis. Figure 5(c) shows that S1P siRNA effectively reduced the upregulated expression levels of S1P proteins induced by AOPP.

The mRNA expression levels of AT1R and ACE in the AOPP group were upregulated compared with those in the CTR group $(p<0.05)$, and these increases were blocked by PF429242 or S1P siRNA ( $p<0.05$, Figures 5(e) and 5(f)).

Cell lysates and medium were collected and assayed for oxidative stress markers $\mathrm{H}_{2} \mathrm{O}_{2}$ and TBARS by using ELISA to test whether S1P-derived SPRR influenced the activation of renal oxidative stress induced by AOPP in HK-2 cells. Medium $\mathrm{H}_{2} \mathrm{O}_{2}$ and TBARS were higher in the AOPP group than in the CTR group $(p<0.05)$, and this expression was blocked by PF429242 ( $p<0.05$, Figures $5(\mathrm{~g})$ and $5(\mathrm{~h}))$.

3.6. AOPP Induced Activation of the Nox4/ $\mathrm{H}_{2} \mathrm{O}_{2}$ Pathway, and Inhibition of S1P-Derived sPRR Significantly Inhibited It. ROS includes superoxide anion, $\mathrm{H}_{2} \mathrm{O}_{2}$, hydroxyl radical, and so on [36]. The Nox families catalyze the regulated formation of ROS [37]. Among these Noxs, we found that AOPP induced significant upregulation of Nox4 on mRNA levels but Nox1, Nox2, Nox3, and Nox 5 showed no significant difference at the mRNA levels compared to the AOPP group in HK-2 cells as assessed by qRT-PCR (Supplementary Figure 2A-E). Nox4 mainly produces $\mathrm{H}_{2} \mathrm{O}_{2}$ rather than superoxide anions, while other Nox isoforms present in the cardiovascular system (i.e., Nox1, Nox2, Nox3, and Nox5) produce superoxide anions as their primary products [4]. In other words, the downstream expression product of $\mathrm{Nox} 4$ is $\mathrm{H}_{2} \mathrm{O}_{2}$ [38].

AOPP could induce the increase in Nox4 protein expression, and Nox4 siRNA completely silenced it (Figure 6(a)). Nox4 knockdown suppressed AOPP-induced Nox4 upregulation at the mRNA level $(p<0.05$, Supplementary Figure 1B). In addition, Nox4 siRNA treatment did not affect the AOPP-induced medium sPRR secretion in HK-2 cells ( $p>0.05$, Supplementary Figure 1C). Therefore, Nox4 may be a downstream target of PRR/sPRR signaling.

AOPP-induced cell lysate $\mathrm{H}_{2} \mathrm{O}_{2}$ significantly increased, and this increase was blocked by PF429242 treatment $(p<0.05$, Figure 6(b)). As shown in Figure 6(c), PF429242 almost completely blunted the AOPP-induced upregulated expression of Nox $4(p<0.05$, Figure 6(b)), and an exogenous recombinant protein-sPRR-His rescued this phenomenon. 


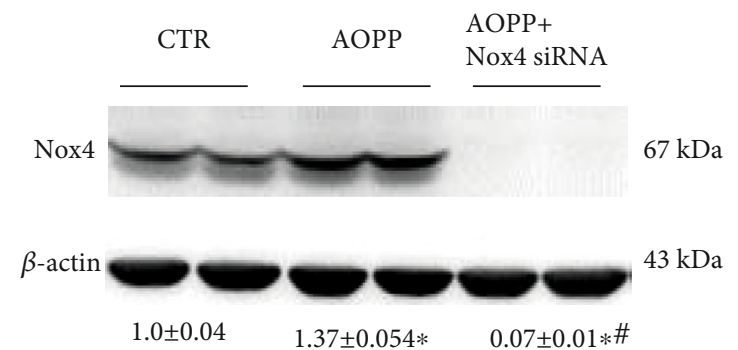

(a)

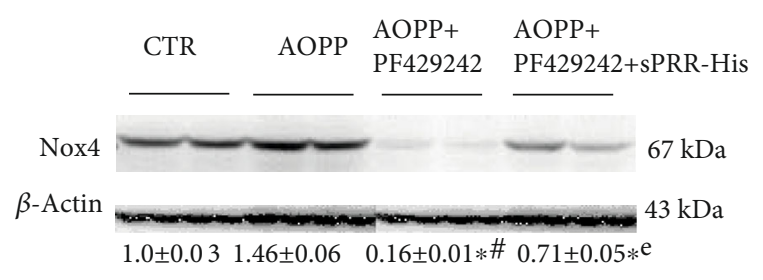

(c)

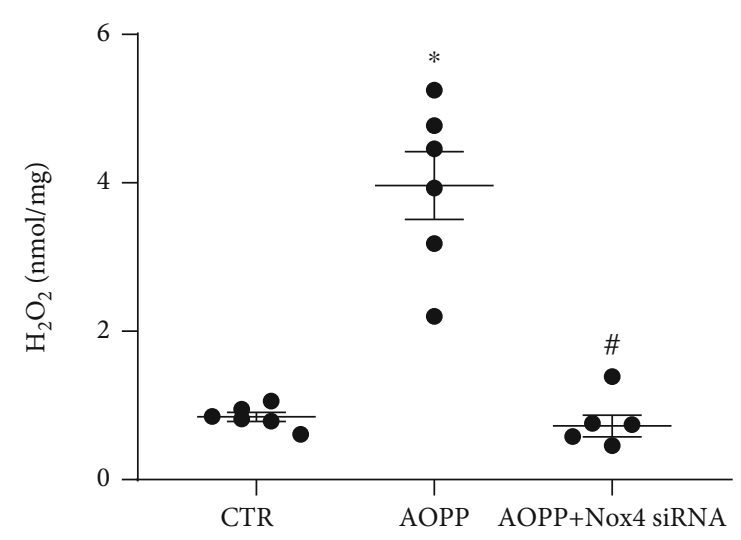

(b)

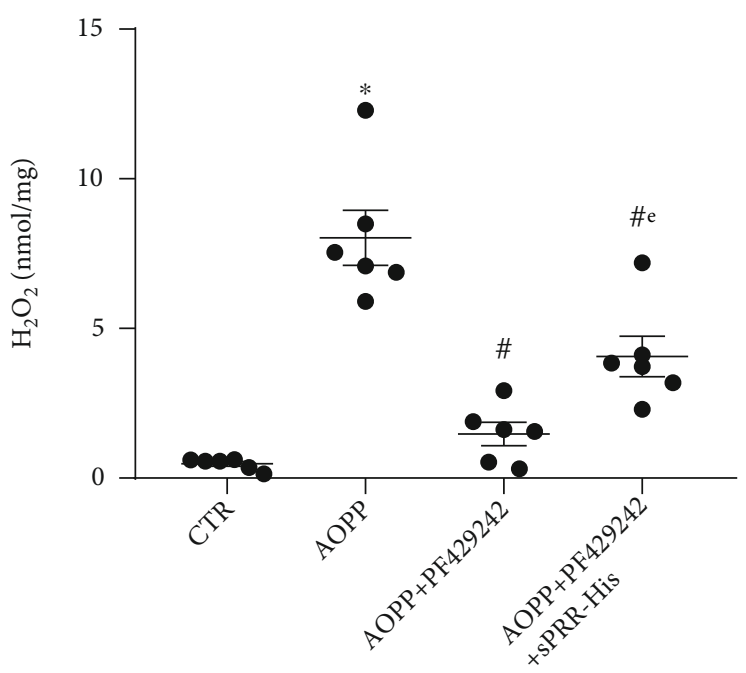

(d)

FIgURE 6: AOPP treatment-induced Nox4-dependent $\mathrm{H}_{2} \mathrm{O}_{2}$ production was mediated by S1P-derived sPRR in HK-2 cells. (a, b) HK-2 cells were treated up to $24 \mathrm{~h}$ with CTR, AOPP $(100 \mu \mathrm{g} / \mathrm{ml})$, and AOPP+Nox4 siRNA. The expression of Nox4 was determined by Western blotting (a, representative picture) and normalized to $\beta$-actin. Densitometry analysis is shown below Western blotting ( $n=6$ per group). (b) The $\mathrm{H}_{2} \mathrm{O}_{2}$ concentrations in media were determined by ELISA and normalized based on total protein contents ( $n=6$ per group). (c ,d) HK-2 cells were incubated with PF429242 $(40 \mu \mathrm{M})$ and PF429242 $(40 \mu \mathrm{M})+$ sPRR-His $(50 \mathrm{nM})$ for $1 \mathrm{~h}$ and then treated with AOPP $(100 \mu \mathrm{g} / \mathrm{ml})$ for $24 \mathrm{~h}$. The expression levels of Nox4 were subjected to SDS-PAGE and Western blotting (c, representative picture) and normalized to $\beta$-actin. Densitometry analysis is shown below Western blotting ( $n=6$ per group). (d) The contents of $\mathrm{H}_{2} \mathrm{O}_{2}$ in media were determined by ELISA and normalized based on total protein contents ( $n=6$ per group). ${ }^{*} p<0.05$ versus CTR; ${ }^{\#} p<0.05$ versus AOPP; and ${ }^{\mathrm{e}} p<0.05$ versus AOPP + PF429242. Data are mean \pm SE. $n=6$ per group, where $n$ is the sample size per group. In all transfection experiments, the samples CTR and AOPP indicated the transfected cells with control nontargeting siRNA. All experiments were repeated independently twice with similar results, and all attempts of replication were successful.

Similar results were obtained by ELISA analysis of $\mathrm{H}_{2} \mathrm{O}_{2}$ $(p<0.05$, Figure 6(c)). AOPP induced the increase in cell lysate $\mathrm{H}_{2} \mathrm{O}_{2}$ expression, which was significantly inhibited by PF429242 and further reversed by sPRR-His $(p<0.05$, Figure 6(d)).

\section{Discussion}

AOPP was discovered by Witko-Sarsat et al. in 1996 in the plasma of patients who developed chronic renal failure [39]. It is one of the specific markers of protein oxidation, and it is related to the damage of oxygen free radicals in the body and oxidative stress reaction [40]. AOPP is a prod- uct of oxidative stress, and it may induce or aggravate oxidative stress response and chronic inflammation [41]. It is an independent predictor of renal injury in patients with CKD [42]. The level of AOPP was positively correlated with the degree of renal function injury $[43,44]$. In addition, a growing body of evidence suggested that AOPP could promote the progression of CKD and induce the apoptosis of podocytes, damage of renal tubular epithelium, and proliferation and differentiation of renal mesangial cells [12, 45-47]. Studies suggested that AOPP could induce the rapid generation of oxygen free radicals' $\left(0^{2-}\right)$ renal epithelial cell line, leading to the activation of Nox, which is similar to phagocytes and mainly derived from tubular epithelial cells, and 
the increase in ROS production [48]. A previous study well demonstrated that AOPP contributed to the intrarenal RAS activation involvement of CD36-dependent signaling [10]. However, whether AOPP could activate fPRR and the extracellular domain of soluble PRR-sPRR, a new member of RAS, is unclear. In the current study, AOPP induced PRR to be cleaved by S1P to generate SPRR, which then activated intrarenal RAS. Meanwhile, sPRR mediated oxidative stress response by affecting the $\mathrm{Nox} 4 / \mathrm{H}_{2} \mathrm{O}_{2}$ pathway. Moreover, we also found that Nox4 siRNA treatment did not affect AOPP-induced medium sPRR secretion in HK-2 cells. Therefore, we speculated that other pathways irrelevant to oxidative stress should be included in the secretion of sPRR. Indeed, antioxidant treatment was not sufficient to halt the vicious circle of cause and causality in renal injury. The phenomenon was similar to that found in a previous study [49]. In the Heart Outcomes Prevention Evaluation (HOPE) study, vitamin E (an antioxidant) administered daily for four to six years had no beneficial effects on cardiovascular outcomes in patients at high risk for cardiovascular events.

RAS plays an important role in the occurrence and progression of nephropathy [50]. In particular, clinical use of ACEI and ARB could effectively control blood pressure and reduce renal injury, such as proteinuria [51]. fPRR is highly expressed in renal tubules, and it has a potential role in renal RAS regulation [52]. Many studies have shown that fPRR could aggravate tissue damage, such as promoting the development of hypertension, diabetic nephropathy, and proteinuria nephropathy, by activating local RAS in tissues and activating the role of proinflammatory and profibrosis factors $[34,53-56]$. The data in the present study showed that PPRR inhibitors PRO20 and fPRR siRNA could significantly inhibit the AOPP-induced expression levels of AGT, ACE, AT1R, and Ang II in HK-2 cells. Therefore, these novel findings may provide a new therapeutic target for early intervention in the treatment of CKD. Conceivably, the AOPP-related oxidative stress and inflammation to activate RAS and Nox $4 / \mathrm{H}_{2} \mathrm{O}_{2}$ signaling may be a new therapeutic target for renal intervention in CKD.

Evidence from literature suggested that furin or ADAM19 cleaved fPRR to sPRR, but the phenomenon remains controversial [57, 58]. Recent studies have well identified that a novel proprotein convertase, called S1P, is the primary protease responsible for cleaving and producing sPRR [16, 17]. In the present study, the S1P inhibitor PF429242 significantly reduced the production of sPRR induced by AOPP. Moreover, two furin inhibitors effectively inhibited fPRR cleavage, but they did not affect sPRR secretion. We also found that mRNA levels of PRR were modestly elevated in treatment with furin inhibitor I compared to AOPP treatment. Such interesting phenomenon needs further investigation. We speculated that a novel sPRR that has not yet been detected by Western blotting and ELISA may be present, which could be cleaved by furin. While we did not have direct evidence, we suspected that furin inhibition reduced the production of the novel sPRR, which further elicited the upregulation of PRR mRNA levels. Overall, these findings extended the previous observations and supported the notion that S1P is the major protease respon- sible for the cleavage and production of sPRR. Previous studies showed that $\mathrm{SPRR}$ promoted inflammation via the Nox4/NF- $\kappa$ B pathway and upregulated IL-6, IL-8, and VCAM-1 [31]. Another study highlighted the role of sPRR in renal fibrosis, where sPRR was shown to promote fibronectin in HK-2 cells via the activation of the $\mathrm{AKT} / \beta$ catenin/snail pathway [28]. The present study revealed that AOPP could activate not only renal RAS but also the Nox $4 / \mathrm{H}_{2} \mathrm{O}_{2}$ pathway. Inhibition of sPRR could not only reduce the expression levels of renin, Ang II, AGT, ACE, and AT1R but also directly regulate the expression of Nox4 and further affect the production of $\mathrm{H}_{2} \mathrm{O}_{2}$ in $\mathrm{HK}-2$ cells. Meanwhile, sPRR-His rescued the expression of Nox4 and the production of $\mathrm{H}_{2} \mathrm{O}_{2}$. These results suggested that sPRR could affect the oxidative stress injury of proximal tubule epithelial cells through RAS-dependent and RASindependent pathways.

Oxidative stress is one of the factors that cause chronic vascular disease [59]. As an important subtype of NADPH oxidase, Nox4 is highly expressed in the kidney, and it could catalyze the production of $\mathrm{H}_{2} \mathrm{O}_{2}$ [60]. PRR regulates the stimulating activation of $\alpha-\mathrm{ENaC}$ by regulating Nox4mediated $\mathrm{H}_{2} \mathrm{O}_{2}$ production [61]. In the present study, sPRR-His and the S1P inhibitor PF429242 were used to investigate the role of SPRR in Nox4 regulation by AOPP. The results showed that AOPP-induced Nox4 expression was significantly inhibited after inhibiting sPRR production, while exogenous sPRR-His recombinant protein could upregulate Nox4 expression. Based on these results, sPRRHis may be involved in regulating the expression of Nox4. However, the specific molecular mechanism of Nox4 by sPRR is still missing, which could be explored in future experiments.

Taken together, this study demonstrated that the sPRR in renal tubular epithelial cells plays an important physiological and pathophysiological role in renal oxidative stress and inflammation through activating intrarenal RAS and Nox4/ $\mathrm{H}_{2} \mathrm{O}_{2}$ signaling induced by AOPP.

\section{Data Availability}

No data were used to support this study.

\section{Conflicts of Interest}

The authors declare that they have no conflicts of interest.

\section{Acknowledgments}

This research was funded by grants from the National Natural Science Foundation of China (82000400), the PhD Start-up Funds of Weifang Medical University (02186901), and the Weifang Science and Technology Development Plan (2021YX043) and partially funded by the Provincial Undergraduate Training Programs for Innovation and Entrepreneurship (S202110438054), the Visiting Scholar Project of Weifang Medical University (20217-14), and the Student Innovation Program of Weifang Medical University (X2021386 and X2021370). 


\section{Supplementary Materials}

Supplementary 1. Supplementary Figure 1: (A) HK-2 cells were treated up to $24 \mathrm{~h}$ with CTR, AOPP $(100 \mu \mathrm{g} / \mathrm{ml})$, and AOPP+furin inhibitor I. (B and C) HK-2 cells were treated up to $24 \mathrm{~h}$ with CTR, AOPP $(100 \mu \mathrm{g} / \mathrm{ml})$, and AOPP+Nox4 siRNA. (B) The level of Nox4 mRNA was determined by qRT-PCR and normalized to GAPDH. (C) Medium sPRR. ELISA data normalized with protein concentrations $(n=6$ per group). ${ }^{*} p<0.05$ versus CTR; ${ }^{*} p<0.05$ versus AOPP. Data are mean \pm SE. $n=6$ per group, where $n$ is the sample size per group.

Supplementary 2. Supplementary Figure 2: HK-2 cells were treated up to $24 \mathrm{~h}$ with CTR and AOPP $(100 \mu \mathrm{g} / \mathrm{ml})$. The levels of Nox1, Nox2, Nox3, Nox4, and Nox 5 mRNA were determined by qRT-PCR and normalized to GAPDH. (A) Nox1 mRNA, (B) Nox2 mRNA, (C) Nox3 mRNA, (D) Nox4 mRNA, and (E) Nox5 mRNA. ${ }^{*} p<0.05$ versus CTR. n.s.: nonsignificant. Data are mean \pm SE. $n=6$ per group, where $n$ is the sample size per group.

\section{References}

[1] M. Ruiz-Ortega, S. Rayego-Mateos, S. Lamas, A. Ortiz, and R. R. Rodrigues-Diez, "Targeting the progression of chronic kidney disease," Nature Reviews. Nephrology, vol. 16, no. 5, pp. 269-288, 2020.

[2] V. Jha, G. Garcia-Garcia, K. Iseki et al., "Chronic kidney disease: global dimension and perspectives," The Lancet, vol. 382, no. 9888, pp. 260-272, 2013.

[3] R. N. Moresco, M. B. Sangoi, J. A. M. de Carvalho, E. Tatsch, and G. V. Bochi, "Diabetic nephropathy: traditional to proteomic markers," Clinica Chimica Acta, vol. 421, pp. 17-30, 2013.

[4] G. K. Buchmann, C. Schürmann, T. Warwick et al., "Deletion of NoxO1 limits atherosclerosis development in female mice," Redox Biology, vol. 37, 2020.

[5] Y. Tian, M. Fan, Z. Qin et al., "Hydrogen peroxide positively regulates brassinosteroid signaling through oxidation of the BRASSINAZOLE-RESISTANT1 transcription factor," Nature Communications, vol. 9, no. 1, 2018.

[6] S. Cho, S. L. Yu, J. Kang et al., "NADPH oxidase 4 mediates TGF- $\beta 1 /$ Smad signaling pathway induced acute kidney injury in hypoxia," PLoS One, vol. 14, no. 7, article e0219483, 2019.

[7] O. Lowe, F. Rezende, J. Heidler, I. Wittig, V. Helfinger, R. P. Brandes et al., "BIAM switch assay coupled to mass spectrometry identifies novel redox targets of NADPH oxidase 4," Redox Biology, vol. 21, 2019.

[8] M. Cristani, A. Speciale, A. Saija, S. Gangemi, P. L. Minciullo, and F. Cimino, "Circulating advanced oxidation protein products as oxidative stress biomarkers and progression mediators in pathological conditions related to inflammation and immune dysregulation," Current Medicinal Chemistry, vol. 23, no. 34, pp. 3862-3882, 2016.

[9] O. Dzydzan, I. Brodyak, A. Sokol-Letowska, A. Z. Kucharska, and N. Sybirna, "Loganic acid, an iridoid glycoside extracted from Cornus mas L. fruits, reduces of carbonyl/oxidative stress biomarkers in plasma and restores antioxidant balance in leukocytes of rats with streptozotocin-induced diabetes mellitus," Life, vol. 10, no. 12, 2020.
[10] W. Cao, J. Xu, Z. M. Zhou, G. B. Wang, F. F. Hou, and J. Nie, "Advanced oxidation protein products activate intrarenal renin-angiotensin Systemviaa CD36-mediated, redox-dependent pathway," Antioxidants \& Redox Signaling, vol. 18, no. 1, pp. 19-35, 2013.

[11] X. Chen, W. Liu, J. Xiao et al., "FOXO3a accumulation and activation accelerate oxidative stress-induced podocyte injury," The FASEB Journal, vol. 34, no. 10, pp. 1330013316, 2020.

[12] X. Li, T. Zhang, J. Geng et al., "Advanced oxidation protein products promote lipotoxicity and tubulointerstitial FibrosisviaCD36/ $\beta$-Catenin pathway in diabetic nephropathy," Antioxidants \& Redox Signaling, vol. 31, no. 7, pp. 521-538, 2019.

[13] J. Zhang, X. Xiang, S. Shu et al., "Advanced oxidation protein products inhibit the autophagy of renal tubular epithelial cells," Experimental and Therapeutic Medicine, vol. 15, pp. 3908-3916, 2018.

[14] G. Nguyen, F. Delarue, C. Burckle, L. Bouzhir, T. Giller, and J. D. Sraer, "Pivotal role of the renin/prorenin receptor in angiotensin II production and cellular responses to renin," The Journal of Clinical Investigation, vol. 109, no. 11, pp. 1417-1427, 2002.

[15] G. Nguyen, "Renin, (pro)renin and receptor: an update," Clinical Science (London, England), vol. 120, no. 5, pp. 169-178, 2011.

[16] H. Fang, C. Xu, A. Lu et al., "(Pro)renin receptor mediates albumin-induced cellular responses: role of site-1 proteasederived soluble (pro)renin receptor in renal epithelial cells," American Journal of Physiology. Cell Physiology, vol. 313, no. 6, pp. C632-C643, 2017.

[17] T. Nakagawa, C. Suzuki-Nakagawa, A. Watanabe et al., "Site-1 protease is required for the generation of soluble (pro)renin receptor," Journal of Biochemistry, vol. 161, no. 4, pp. 369379, 2017.

[18] Y. Ikeda, K. Tsutsui, Y. Yamada, R. Kato, T. Muramatsu, and T. Senbonmatsu, "Relationship between soluble (pro)renin receptor and renin activity in patients with severe heart failure," Journal of Clinical Medicine, vol. 9, no. 12, 2020.

[19] Y. Amari, S. Morimoto, F. Nakajima, T. Ando, and A. Ichihara, "Serum soluble (pro)renin receptor levels in maintenance hemodialysis patients," PLoS One, vol. 11, no. 7, 2016.

[20] Y. Amari, S. Morimoto, T. Iida et al., "Association between serum soluble (pro)renin receptor level and worsening of cardiac function in hemodialysis patients: a prospective observational study," PLoS One, vol. 15, no. 5, 2020.

[21] D. Watanabe, S. Morimoto, N. Morishima, Y. Kato, Y. Nagashima, N. Shibata et al., "Adrenal (pro)renin receptor expression and serum soluble (pro)renin receptor concentration in primary aldosteronism," International Journal of Endocrinology, vol. 2020, Article ID 9640103, 9 pages, 2020.

[22] F. Wang, R. Luo, C. J. Zou et al., "Soluble (pro)renin receptor treats metabolic syndrome in mice with diet-induced obesity via interaction with PPAR $\gamma$," JCI Insight, vol. 5, no. 7, 2020.

[23] Q. Zhu and T. Yang, "Enzymatic sources and physiopathological functions of soluble (pro)renin receptor," Current Opinion in Nephrology and Hypertension, vol. 27, no. 2, pp. 77-82, 2018.

[24] F. Wang, R. Luo, K. Peng et al., "Soluble (pro)renin receptor regulation of $\mathrm{ENaC}$ involved in aldosterone signaling in cultured collecting duct cells," American Journal of Physiology. Renal Physiology, vol. 318, no. 3, pp. F817-F825, 2020. 
[25] K. T. Yang, T. Yang, and J. D. Symons, "Soluble (pro)renin receptor as a potential therapy for diabetes insipidus," American Journal of Physiology. Renal Physiology, vol. 315, no. 5, pp. F1416-F1421, 2018.

[26] Y. Feng, K. Peng, R. Luo, F. Wang, and T. Yang, "Site-1 protease-derived soluble (pro)renin receptor contributes to angiotensin II-induced hypertension in mice," Hypertension, vol. 77, no. 2, pp. 405-416, 2021.

[27] E. Gatineau, G. Arthur, A. Poupeau et al., "The prorenin receptor and its soluble form contribute to lipid homeostasis," American Journal of Physiology. Endocrinology and Metabolism, vol. 320, no. 3, pp. E609-E618, 2021.

[28] S. Xie, J. Su, A. Lu et al., "Soluble (pro)renin receptor promotes the fibrotic response in renal proximal tubule epithelial cells in vitro via the Akt/ $\beta$-catenin/Snail signaling pathway," American Journal of Physiology. Renal Physiology, vol. 319, no. 5, pp. F941-F953, 2020.

[29] F. Wang, C. Xu, R. Luo et al., "Site-1 protease-derived soluble (pro)renin receptor targets vasopressin receptor 2 to enhance urine concentrating capability," JCI Insight, vol. 4, no. 7, 2019.

[30] X. Lu, F. Wang, C. Xu et al., "Soluble (pro)renin receptor via $\beta$ catenin enhances urine concentration capability as a target of liver X receptor," Proceedings of the National Academy of Sciences of the United States of America, vol. 113, no. 13, pp. E1898-E1906, 2016.

[31] Z. Fu, F. Wang, X. Liu et al., "Soluble (pro)renin receptor induces endothelial dysfunction and hypertension in mice with diet-induced obesity via activation of angiotensin II type 1 receptor," Clinical Science (London, England), vol. 135, no. 6, pp. 793-810, 2021.

[32] W. Li, M. N. Sullivan, S. Zhang et al., "Intracerebroventricular infusion of the (pro)renin receptor antagonist PRO20 attenuates deoxycorticosterone acetate-salt-induced hypertension," Hypertension, vol. 65, no. 2, pp. 352-361, 2015.

[33] H. Fang, M. Deng, L. Zhang et al., "Role of (pro)renin receptor in albumin overload-induced nephropathy in rats," American Journal of Physiology. Renal Physiology, vol. 315, no. 6, pp. F1759-F1768, 2018.

[34] Y. Wang, Y. Wang, K. Xue et al., "(Pro)renin receptor antagonist PRO20 attenuates nephrectomy-induced nephropathy in rats via inhibition of intrarenal RAS and $\mathrm{Wnt} / \beta$-catenin signaling," Physiological Reports, vol. 9, no. 11, article e14881, 2021.

[35] V. Witko-Sarsat, M. Friedlander, T. N. Khoa et al., "Advanced oxidation protein products as novel mediators of inflammation and monocyte activation in chronic renal failure," Journal of Immunology, vol. 161, pp. 2524-2532, 1998.

[36] H. Zhu, G. Chen, Y. Wang et al., "Dimethyl fumarate protects nucleus pulposus cells from inflammation and oxidative stress and delays the intervertebral disc degeneration," Experimental and Therapeutic Medicine, vol. 20, no. 6, p. 1, 2020.

[37] D. Gianni, B. Diaz, N. Taulet, B. Fowler, S. A. Courtneidge, and G. M. Bokoch, "Novel p47phox-Related organizers regulate localized NADPH oxidase 1 (Nox1) activity," Science Signaling, vol. 2, no. 88, 2009.

[38] J. Xie, E. Hong, B. Ding et al., "Inhibition of NOX4/ROS suppresses neuronal and blood-brain barrier injury by attenuating oxidative stress after intracerebral hemorrhage," Frontiers in Cellular Neuroscience, vol. 14, article 578060, 2020.

[39] V. Witko-Sarsat, M. Friedlander, C. Capeillère-Blandin et al., "Advanced oxidation protein products as a novel marker of oxidative stress in uremia," Kidney International, vol. 49, no. 5, pp. 1304-1313, 1996.

[40] Y. Zhao, L. Zhang, X. Ouyang et al., "Advanced oxidation protein products play critical roles in liver diseases," European Journal of Clinical Investigation, vol. 49, no. 6, article e13098, 2019.

[41] A. Duni, V. Liakopoulos, S. Roumeliotis, D. Peschos, and E. Dounousi, "Oxidative stress in the pathogenesis and evolution of chronic kidney disease: untangling Ariadne's thread," International Journal of Molecular Sciences, vol. 20, no. 15, 2019.

[42] W. Cao, F. F. Hou, and J. Nie, "AOPPs and the progression of kidney disease," Kidney International Supplement, vol. 2014, no. 4, pp. 102-106, 2011.

[43] A. Piwowar, "Biochemical and clinical aspects of advanced oxidation protein products in kidney diseases and metabolic disturbances," Postępy Higieny i Medycyny Doświadczalnej (Online), vol. 68, pp. 179-190, 2014.

[44] B. Liu, X. Hou, Q. Zhou, J. Tian, P. Zhu, J. Xu et al., "Detection of advanced oxidation protein products in patients with chronic kidney disease by a novel monoclonal antibody," Free Radical Research, vol. 45, no. 6, pp. 662-671, 2011.

[45] H. Y. Li, F. F. Hou, X. Zhang et al., “Advanced oxidation protein products accelerate renal fibrosis in a remnant kidney model," Journal of the American Society of Nephrology, vol. 18, no. 2, pp. 528-538, 2007.

[46] Y. Iwao, K. Nakajou, R. Nagai et al., "CD36 is one of important receptors promoting renal tubular injury by advanced oxidation protein products," American Journal of Physiology. Renal Physiology, vol. 295, no. 6, pp. F1871-F1880, 2008.

[47] X. F. Wei, Q. G. Zhou, F. F. Hou, B. Y. Liu, and M. Liang, "Advanced oxidation protein products induce mesangial cell perturbation through PKC-dependent activation of NADPH oxidase," American Journal of Physiology. Renal Physiology, vol. 296, no. 2, pp. F427-F437, 2009.

[48] L. Selmeci, “Advanced oxidation protein products (AOPP): novel uremic toxins, or components of the non-enzymatic antioxidant system of the plasma proteome?", Free Radical Research, vol. 45, no. 10, pp. 1115-1123, 2011.

[49] Heart Outcomes Prevention Evaluation Study I, S. Yusuf, G. Dagenais, J. Pogue, J. Bosch, and P. Sleight, "Vitamin E supplementation and cardiovascular events in high-risk patients," The New England Journal of Medicine, vol. 342, pp. 154-160, 2000.

[50] S. Panizo, L. Martínez-Arias, C. Alonso-Montes et al., "Fibrosis in chronic kidney disease: pathogenesis and consequences," International Journal of Molecular Sciences, vol. 22, no. 1, p. 408, 2021.

[51] R. D. Hill and P. N. Vaidya, Angiotensin II Receptor Blockers (ARB), StatPearls, Treasure Island (FL), 2021.

[52] T. Yang and C. Xu, "Physiology and pathophysiology of the intrarenal renin-angiotensin system: an update," Journal of the American Society of Nephrology, vol. 28, no. 4, pp. 10401049, 2017.

[53] N. Ramkumar and D. E. Kohan, "The (pro)renin receptor: an emerging player in hypertension and metabolic syndrome," Kidney International, vol. 95, no. 5, pp. 1041-1052, 2019.

[54] S. Akhtar and H. M. Siragy, "Pro-renin receptor suppresses mitochondrial biogenesis and function via AMPK/SIRT-1/ PGC- $1 \alpha$ pathway in diabetic kidney," PLoS One, vol. 14, no. $12,2019$. 
[55] C. Li, L. C. Matavelli, S. Akhtar, and H. M. Siragy, “(Pro)renin receptor contributes to renal mitochondria dysfunction, apoptosis and fibrosis in diabetic mice," Scientific Reports, vol. 9, no. 1, 2019.

[56] G. Arthur, J. L. Osborn, and F. B. Yiannikouris, "(Pro)renin receptor in the kidney: function and significance," American Journal of Physiology. Regulatory, Integrative and Comparative Physiology, vol. 320, no. 4, pp. R377-R383, 2021.

[57] A. Yoshikawa, Y. Aizaki, K. Kusano et al., "The (pro)renin receptor is cleaved by ADAM19 in the Golgi leading to its secretion into extracellular space," Hypertension Research, vol. 34, no. 5, pp. 599-605, 2011.

[58] C. Cousin, D. Bracquart, A. Contrepas, P. Corvol, L. Muller, and G. Nguyen, "Soluble form of the (pro)renin receptor generated by intracellular cleavage by furin is secreted in plasma," Hypertension, vol. 53, no. 6, pp. 1077-1082, 2009.

[59] F. Santilli, D. D'Ardes, and G. Davi, "Oxidative stress in chronic vascular disease: from prediction to prevention," Vascular Pharmacology, vol. 74, pp. 23-37, 2015.

[60] A. C. Montezano, D. Burger, G. S. Ceravolo, H. Yusuf, M. Montero, and R. M. Touyz, "Novel Nox homologues in the vasculature: focusing on Nox4 and Nox5," Clinical Science, vol. 120, no. 4, pp. 131-141, 2011.

[61] X. Lu, F. Wang, M. Liu et al., "Activation of ENaC in collecting duct cells by prorenin and its receptor PRR: involvement of Nox4-derived hydrogen peroxide," American Journal of Physiology. Renal Physiology, vol. 310, no. 11, pp. F1243-F1250, 2016. 